\title{
Comparative Histological and Ultrastructural Studies on Lung of The Egyptian Hoopoe (Upupa epops major) and The European Hoopoe (Upupa epops epops)
}

\author{
Neveen E. R. El-Bakary ${ }^{1}$, Adel A. Ibrahim², Gamal A. Abd-Allah ${ }^{1}$, Sobhy E. Hasab El-Naby ${ }^{3}$ and Lamiaa E. \\ Deef $^{1}$ \\ ${ }^{1}$ Zoology Department, Damietta Faculty of Science, Damietta University, New Damietta, Egypt \\ ${ }^{2}$ Department of Environmental Science, Faculty of Science, Suez Canal University Suez, Egypt \\ ${ }^{3}$ Zoology Department, Faculty of Science, Menoufiya University, Menoufiya, Egypt
}

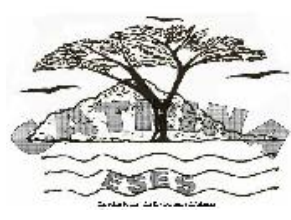

\section{AbSTRACT}

The lung of birds is the most complex and efficient gas exchanger that has evolved in the air-breathing vertebrates. Lung tissues of the Egyptian hoopoe (upupa epops major) and the European hoopoe (upupa epops epops) which inhabit Damietta governorate in Egypt were subjected to comparative histological and ultrastructural studies. The results showed that the number and shape of the parabronchus, the form of the infundibula as well as the air capillaries (Acs) and the blood capillaries (Bcs) were also differed. The blood gas-barrier (BGB) was thinner in the European hoopoe (migratory species) than that of the Egyptian hoopoe (resident species). The lung of the European hoopoe is very efficient because of the presence of an extremely thin blood gas barrier than that of the Egyptian hoopoe. This could be attributed to the requirement of enormous energy by the European hoopoe which flies for longer distances, and might indicate that the lung components are correlated with the metabolic demands that are in turn set by the behavior and life style of the animal

Key words: Birds, Histology, Hoopoes, Lungs, Ultrastructure.

\section{INTRODUCTION}

Hoopoe, upupa epops, is a colorful bird that is found across Afro-Eurasia, notable for its distinctive crown of feathers. It is the only extant species in the family upupidae. In the sibley-Ahlquist taxonomy, the hoopoe is separated from coraciiformes as a separate order, the upupiformes (Mayer, 2000).

Compared with other organs, the lung possesses certain unique structural and functional attributes. It is the only organ in the body that receives the total cardiac output, a quantity that increases several folds between rest and exercise (Constantionpol et al., 1989; Ritchson, 2009). The avian lung is the most complex and efficient gas exchanger between the respiratory organs (King and Mclelland, 1984). It takes two inspiratory and two expiratory cycles for the inspired air (Fedde, 1980; Maina, 2003).

Maina (2005) reported that the basic structure of the avian respiratory system is similar. Differences exist fine in the details, particularly regarding the extant of development of the parabronchi, the arrangement of the secondary bronchi and the location, connection, number of air sacs, however do occur. The flight requires an unusually large expenditure of energy (Berger and Hart, 1974), necessitating an outstandingly efficient gas exchange system between the air and the blood. In view of this metabolic requirement and the fact that lung diseases are a major problem faced by the commercial poultry industry, the ultrastructural configuration of the epithelial lining of the gas exchange mantle of the avian lung deserve serious attention. The goal of this study is to compare the histological and ultrastructural characteristics of the lungs of the Egyptian (upupa epops major) and the European (upupa epops epops) hoopoes.

\section{MATERIALS AND METHODS \\ The Experimental Animals:}

The Experimental Animals Of The Present Study Included Two Different Bird Species, The Egyptian Hoopoe (Upupa Epops Major) And The European Hoopoe (Upupa Epops Epops) Which Were Collected From Different Habitats Of Damietta Governorate In Egypt (Tharwat, 1997). These Two Species Belong To One Order, Coraciiformes And One Family, Upupidae. Samples Of Each Species Were Caught Using Amist Net Or Picked Up By Some Voluntaries.

\section{Light Microscopy}

The Birds Were Sacrificed Then The Lungs Were Removed. Samples From The Lungs Were Fixed In 10\% Aqueous Formaldehyde Solutions For 48 hrs. Next, The Samples Were Dehydrated In An Ascending Grade Of Ethanol Series, Cleared In Xylene. They Were Embedded In Paraffin Blocks And Were Cut Serially. All Sections Were Stained Using Harris HematoxylinEosin (Bancroft And Stevens, 1997).

\section{Electron Microscopy}

\section{Scanning Electron Microscopy}

Selected tissue samples were dehydrated in ascending concentrations of ethanol, critical- point dried in liquid carbon dioxide and subsequently sputter-coated with gold (Andrew et al., 2001).The specimens were mounted on aluminum stubs and viewed on JMS scanning electron microscope at Electron Microscopy Unit in Faculty of Science, Alexandria University. 


\section{Transmission Electron Microscopy}

Another Samples from the Lungs Were Fixed In 2.5\% Gluteraldehyde at $4{ }^{\circ} \mathrm{c}$ in $0.1 \mathrm{M} \mathrm{Na}$ Cacodylate Buffer at pH 7.4 For about 2-3 hrs. The tissues were then washed in cacodylate buffer several times for about $30 \mathrm{~min}$. The samples were postfixed for $2 \mathrm{hrs}$. in $1 \%$ osmium tetroxide at $\mathrm{pH}$ 7.4. The samples were then washed in the buffer several times overnight at. $4{ }^{\circ} \mathrm{C}$ and then passed through increasing concentration of ethanol, rinsed with $100 \%$ propylene oxide for $1 \mathrm{hr}$. and embedded in araldite expoxy resin. Semithin sections were cut and stained with toluidene blue for examination and orientation. Ultrathin sections were cut at $50-60 \mu \mathrm{m}$ thickness, mounted on copper grids, and stained with uranyl acetate and lead citrate (Makanya et al., 2011). Photographs were taken with a jeol electron microscope at an accelerating voltage of $80 \mathrm{kv}$ at electron microscopy unit in Faculty of Science, Alexandria university.

\section{RESULTS}

Morphologically, the avian respiratory system is separated into the lung (the gas exchanging part) and the air sacs (the non respiratory part). Also, the absence of the diaphragm displaces the lungs of birds to the roof of the coelomic cavity.

\section{Light microscopy}

The air way system of the avian lung comprises three tiered system of air conduits, primary bronchus ( $\mathrm{pb}$ ), secondary bronchus ( $\mathrm{sb}$ ) and tertiary bronchus (pr). The parabronchi (tertiary bronchus) occupy more than the half of the avian lung volume in the form of dense bundles of tubes (Fig. 1a, b, c, d). The wall of each parabronchus was pierced by numerous, more or less pentagonal or hexagonal openings that connect the air lumen with pocket-like compartments named atria (at) (Fig. 1c, d). From the floor of the atria arose a number of funnel-shaped ducts, named infundibula (i), from which originated a complex network of fine anastomosing tubules generally known as air capillaries (Fig. 1c , d). The air capillaries were intimately interlocked with a network of blood capillaries that constitute the gas exchange tissue of the lung.

General histology of the egyptian hoopoe lung was similar to that of the european hoopoe. However, lungs of the european hoopoe revealed larger proportion of exchange tissues (et) (Fig. 1b), besides more parabronchus with different shape comparable with those in lungs of the egyptian one (Fig. 1a, b). The parabronchus $(\mathrm{pl})$ was elongated in shape with wider lumen in the egyptian hoopoe, but it was nearly ovoid with smaller lumen in the european one (Fig. 1c, d). The smooth muscles of the atria (at) were observed in both species (Fig. 1c, d). Infundibula (i) occur in both species (Fig. 1c, d), but more in number and size in the european hoopoe than in the egyptian one (Fig. 2a, b). Intraparabronchus (iprs) septum was present in both the egyptian and european hoopoes (Fig. 2c, d).

\section{Electron microscopy}

The ultrastructures of the lung of the investigated species were divided into:

\section{Air conducting elements}

At the level of the parabronchus, the parabronchial lumen opens into the atria that lead to the infundibulae (i). The infundibulae in turn generate air capillaries (ac). The acs that are located closer to the infundibulae are larger and anatomose less frequently than those lie further away. The ac themselves are heterogeneous, rather rounded structures that vary greatly in size and shape in different locations of the exchange tissue (fig. 3a, b).

\section{Blood conducting elements}

The blood capillaries (bc) are made up of a meshwork of interconnected segments that are wide and anatomose more regularly than ac. The air capillaries and blood capillaries formed the exchange tissue. The air capillaries (ac) are rather round structures that interconnect via short, narrow passageways, while the bc comprise proliferative segments with uniform dimensions. The ac and bc were closely intertwine with each other forming a complex network. The acs were straight, blind-ending tubules that project outwards from the parabronchial lumen. The bcs were direct tubules that run inwards parallel to and in contact with the ac (fig. 3c, d). In addition, a laminated membrane surface was observed on the epithelial cells that lining the tertiary bronchi and atria of the lungs. The laminated surface, which varied greatly in thickness and number of lamination was discontinuous and didn't line the entire lumen. Lamellar osmiophilic inclusions were observed in the cytoplasm of epithelial cells (Fig. 4a, b).

The blood-gas barrier (bgb) consisted of endothelium, basal lamina, and a squamous epithelium lining of the air capillaries. A single basal lamina was always found between the endothelium and epithelium of the tissue barrier. The epithelial liming cell was extremely thin with attenuated cytoplasm which was often not greater than that of the unit membrane. The three layers of the bgb (endothelium, interstitium and epithelium) were usually distinct. Pinocytotic vesicles or inclusions were noticed in the endothelium and the epithelium. The vesicles were larger and more common in the endothelium (Fig. 4c, d). The ultrastructural characteristics of the investigated species were different in some features. The lung of egyptian and european hoopoes contains air capillaries (ac) which were surrounded by blood capillaries (bc). The ac of the egyptian lung showed larger diameter compared with the diameter of ac in the european hoopoe lung (Fig. 3a, b). The number of acs in the lung of the european hoopoe was greater than that of the egyptian one. The acs of the egyptian hoopoe were regularly spherical in shape, while the acs of the european hoopoe have irregular shape. The largest number of bc occur in the european hoopoe (Fig. $3 a, b)$. 
Deef et al.
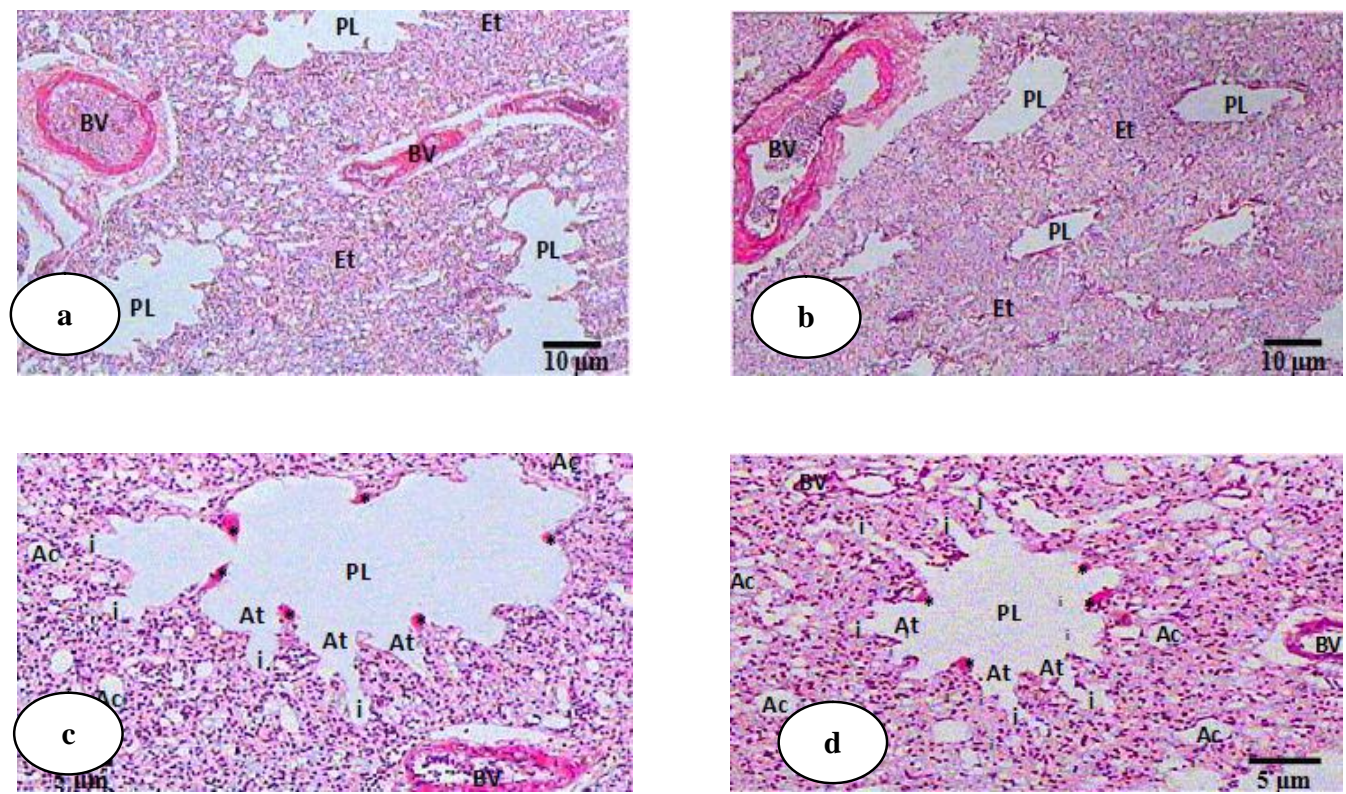

Figure (1): Light micrographs of the lung of Egyptian hoopoe and European hoopoe. (a) and (b):Transverse section of the lung of Egyptian hoopoe. BV blood vessel, PL parabronchial lumina and ET exchange tissue H\&E stain.

(c) and (d): Enlarged part of a transverse section of the lung of Egyptian hoopoe. BV blood vessel, PL parabronchial lumina, smooth muscle (asterisks), Ac air capillary, at atrial area of tertiary bronchus and i the infundibula connect the air exchange area with tertiary bronchial lumen through the atria H\&E stain.
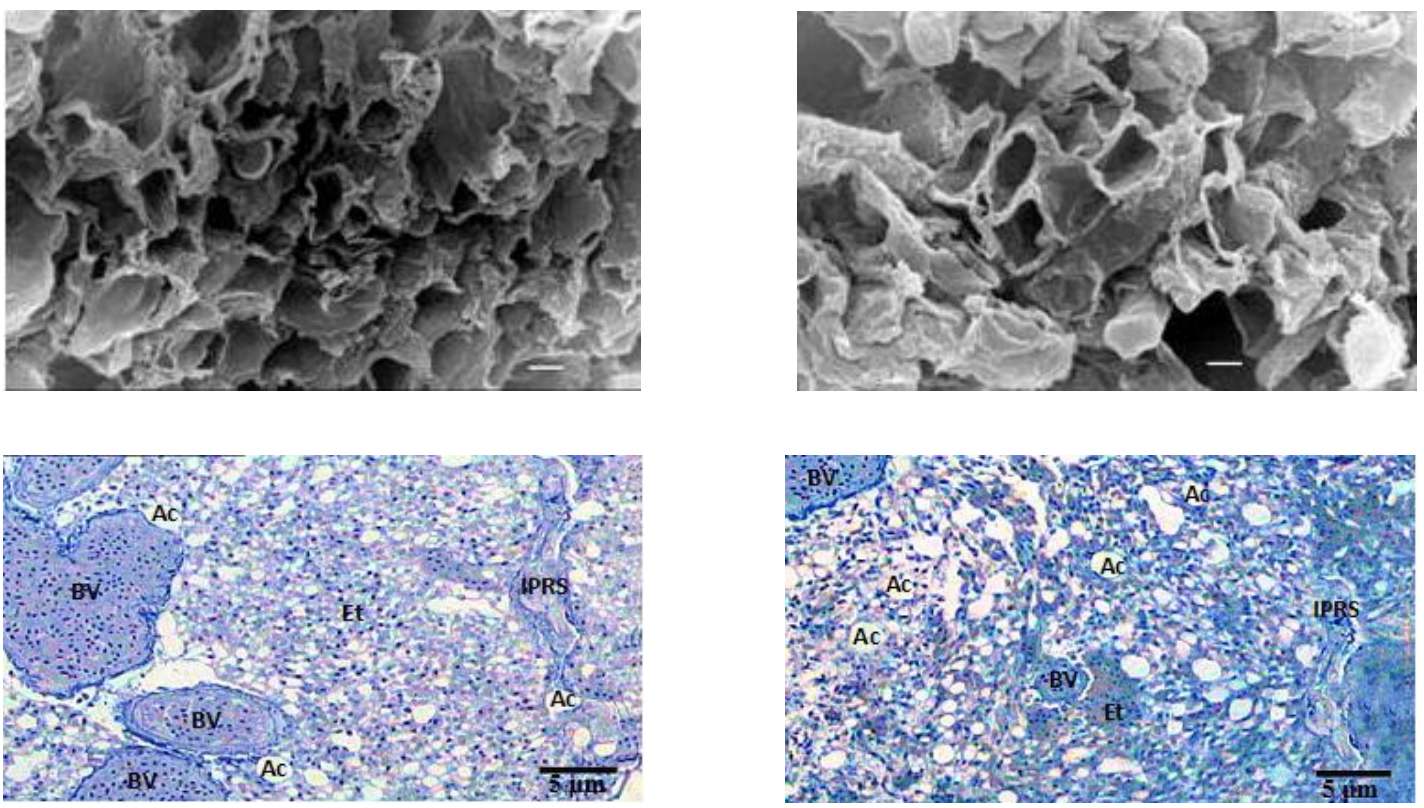

Figure (2): (a) and (b): Scanning lecteron micrograph of a portion of the lung of Egyptian hoopoe. i the infundibula. (c) and (d): Toluidine-blue stained semithin section of the lung of Egyptian hoopoe showing the complex meshwork formed by the Ac air capillary, BV blood capillary containing red blood cells, Et exchange tissue and IPRS intrapulmonary septa. 
The shape of bc of egyptian hoopoe was nearly the same as in the european one. Nucleotide erythrocytes (er) lie in the blood capillary (Fig. 3c, d), and the endothelial cell (ec) appeared in the both species. An osmiophilic surface layer was sometimes observed on the epithelium, but it was usually absent, most due to the fixation process (Fig. 4a, b). The bgb in the lung of the egyptian hoopoe is composed of the thin epithelium of the air capillary separated from the endothelium of the blood capillary by a fused basement membrane. On the other hand, all individual layers were thinner in the european hoopoe compared with that of the egyptian hoopoe (Fig. $4 \mathrm{c}, \mathrm{d})$.

\section{DISCUSSION}

In the present study, the parabronchi showed a great variation in shape and size in both species. However, the parabronchi showed minor variation in the degree of the development of the interparabronchial septa, atria, and atrial muscle. This variation may be related to the different oxygen requirements of the species (Maina et al., 1982; Maina, 2008). Hayek (1960) reported that the main functional feature of the anatomy of the avian bronchial muscle is its system of spiral muscle bands. Anatomically, these appear capable of constricting the lumen of the secondary and tertiary bronchi. As can be inferrred from earlier studies (Jones and Randnor, 1972), during the early stages of the development of the avian lung, the parabronchi (tertiary bronchi) are generally separated by septal connective tissue, giving them somewhat hexagonal in shape. In the studied species, ips (interparabronchial septa) persist throughout life, the ips supports the parabronchial blood vessels (Maina et al., 1982; Maina, 2010). In this study, it was found that the blood capillaries and air capillaries are intertwined and form a meshwork of parenchymal tissue separated by numerous atria in the parabronchi. On the other hand, air capillaries (ac) and blood capillaries (bc) showed a great variation in the size and shape in the two species. (Ac) and (bc) allow the exchange tissue of the invaginated avian respiratory system to be ventilated continuously and unidirectionally, granting exceptionally high respiratory efficiency (Schied, 1979; Fedde, 1980).

In the current study, the granular cells are present in both species, which are steady elements in phylogenesis, they manufacture and discharge osmiophilic lamellar inclusions which are considered to be the precursor of the surfactant responsible for alveolar stability (Gil and Reiss, 1973).

While some authors concluded that distinctive surface activity was absent from the lung of fowl and pigeon (Miller and Bondurant, 1961; Klaus et al., 1962), there were data indicating that the avian lung possesses a surfactant showing similarities with the epiphase of mammalian surfactant, as reported by Pattle (1958; 1963), pattle and hopkinson (1963), and Harlan et al.
(1966). It was shown by chemical analysis of lung washings from the domestic turkey that avian surfactant has a composition similar to that of mammalian lungs (Fujiwara et al., 1970).

The osmiophilic inclusions were first observed in the epithelial cells during preliminary stages of phagocytosis in the avian lung (Tyler and Pangborn, 1964). It is suggested that the laminated membrane surface is intimately associated with the formation of the osmiophilic inclusions. For efficient gas exchange by passive diffusion, a thin and extensive blood gas-barrier bgb is necessary. Maina and king (1982) suggested that the avian lung has evolved a very much thinner blood gas-barrier than that of any other known air breathing vertebrate, but without sacrificing the structural stability of the barrier.

This adaptation maximizes the diffusing capacity of the lung and minimizes the coast in the oxygen incurred by the metabolism of the barrier itself. Thus, birds have achieved perfection in barrier design, and this would contribute to their remarkable to expand energy during flight, especially at high altitude. The present study agreed with that, the blood gas-barrier was thinner in the migratory species (European hoopoe) than the resident species (Egyptian hoopoe). According to Maina et al., (1989) it was reported that the thickness of the blood gas-barrier correlate with the metabolic demands that one intern set by the behavior and the life style of the animal.

The surface activity of the trilaminar substance in the wall of the air capillaries may therefore be of little importance in preventing collapse. The extremely small diameters of the avian air capillaries, with sharp curvatures compared to the mammalian alveoli, will create a greater surface tension.

The constant presence of the trilaminar substance as an integral compound of the lining layer on the air capillaries might be to prevent excessive transudation of plasma from blood capillaries into the air capillaries. An accumulation of fluid into the air spaces of the gas exchange mantle would depreciate the value of the exceptionally thin blood-gas barrier. The trilaminar substance might account to a large degree for the stability of the air capillaries. The role of the trilaminar substance is not known (Pattle, 1978). The arrangement of pairs of attenuated parallel processes of squamous respiratory cells as retinacula through the air capillary lumina may be regarded as an additional "skeletal support' of the avian gas exchange mantle.

In conclusion, the lung components of birds correlated with the metabolic demands of the animals and affects on animal life style as in the Egyptian and European hoopoes. The European hoopoe lung was very efficient because of an extremely thin blood gas barrier than that of the Egyptian hoopoe lung. This could be attributed to the requirement of enormous energy by the European hoopoe which flies for longer distances. 
Deef et al.
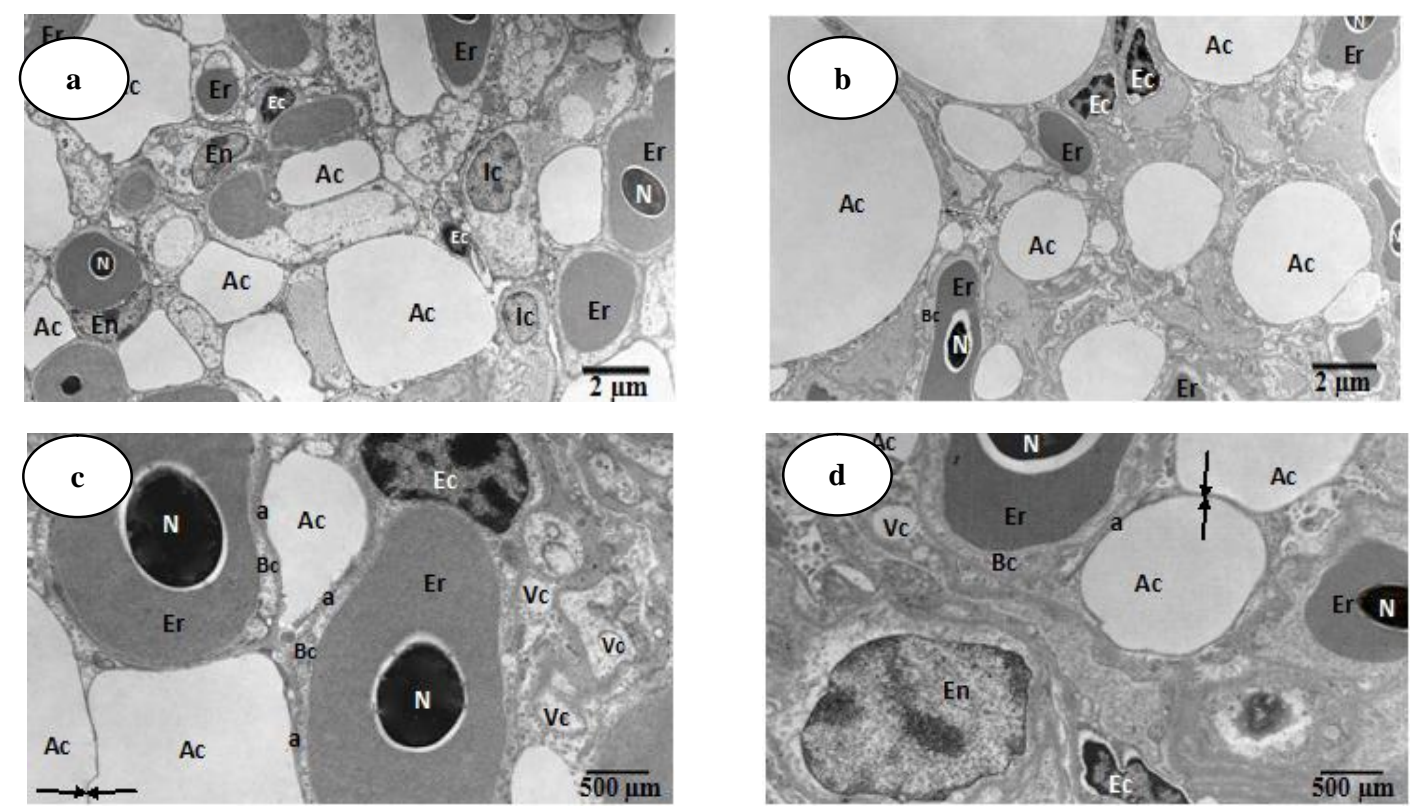

Figure (3): (a) and (b): Transmission electron micrograph of the lung of Egyptian hoopoe, showing Bc blood capillaries containing Er erythrocytes suspended in Ac air capillaries, En endothelial cell, $\mathrm{N}$ nucleus, Ic interstitial cells and perikaryon of an Ec epithelial cell. (c) and (d): A higher magnified part of the lung of Egyptian hoopoe, showing Ac air capillaries, Bc blood capillaries forming a network. Er erythrocytes, arrows areas where air capillaries lie adjacent to each other, Vc micropinocytotic vesicles, $\mathrm{N}$ nucleus, a tissue barrier and Ec epithelial cell.
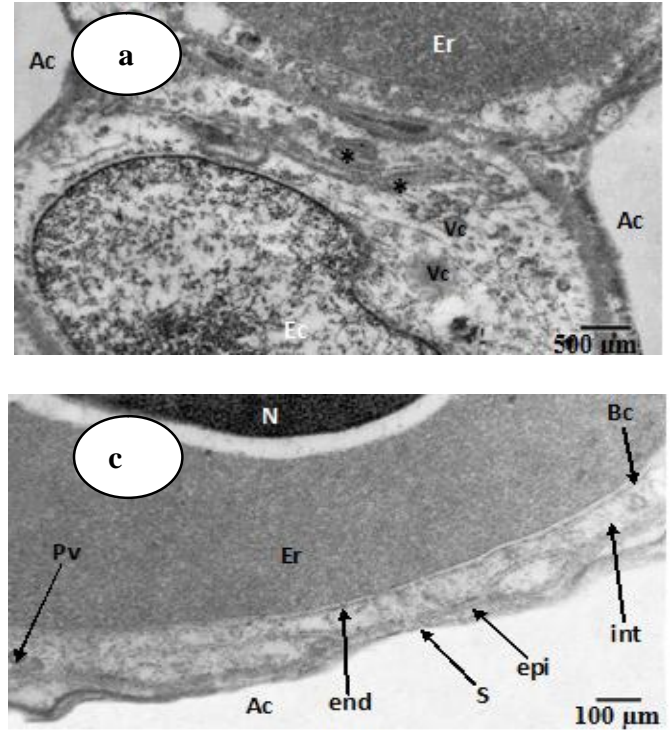
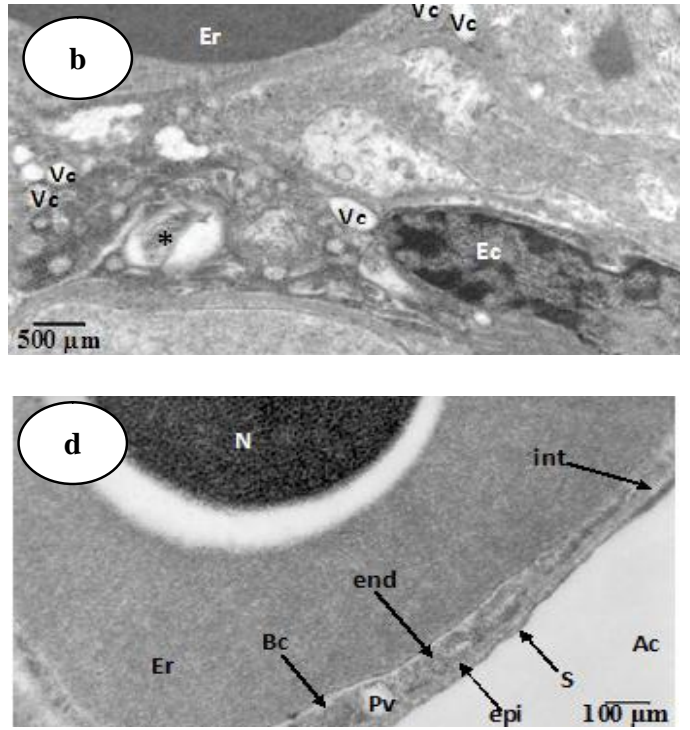

Figure (4): (a) and (b): Transmission electron micrograph of the blood-gas barrier (BGB) of Egyptian hoopoe lung, showing a granular epithelial cell with osmiophilic bodies (asterisks), Vc micropinocytotic vesicles, Ac lumen of air capillary, Er erythrocytes and Ec epithelial cell. (c) and (d): A higher magnified part of blood-gas barrier (BGB) of Egyptian hoopoe lung, showing the constituent of the (BGB), Ac air capillary, Bc lumen of blood capillary, Er erythrocytes, $\mathrm{N}$ nucleus, $\mathrm{S}$ surface layer, epi epithelial cell layer, int interstitial space, end endothelial cell layer and Pv pinocytotic vesicle. 


\section{REFERENCES}

ANDREW, N., P. MALCOLM, N. CHARLES, K. DETER, AND H. PETER. 2001. Morphological analysis of the postnatally developing marsupial lung: the Quokka Wallaby. Anatomical Records. 262: 253265.

BANCROFT, J. D. AND A. STEVENS. 1997. Theory and practice of histological techniques. New York: Churchill living stone.

BERGER, M. AND J. S. HART. 1974. Physiology and energetics of flight. In: Avian Biology, Vol. 4. J.R. King and D.S. Farmer, eds. Academic Press, New York, pp. 415-477.

CONSTANTINOPOL, M., J. H. JONES, E. R. WEIBEL, H. HOPPELAR, A. LIDHOLM, AND R. H. KARAS. 1989. Oxygen transport during exercise in large mammals. II. Oxygen uptake by the pulmonary gas exchanger. Journal of Applied Physiology, 67: 871-878.

FEDDE, M.R. 1980. The structure and gas- flow pattern in the avian respiratory system. Poultry Science. 59: 2642-2653.

FUJIWARA, T., F. H. ADAMS, M. NOZAKI, AND G.B. DERMER. 1970. Pulmonary surfactant phospholipids from turkey lung: Comparison with rabbit lung. American Journal of Physiology, 218: 218-225.

GIL, J. AND O. K. REISS. 1973. Isolation and characterization of lamellar bodies and tubular myelin from rat lung homogenates. Journal of Cell Biology, 58:152-171.

HARLAN, W. R., J. H. MARGRAF, AND S. J. SAID. 1966. Pulmonary lipid composition of species with and without surfactant. American Journal of Physiology. 211: 855-861.

HAYEK, H.V. 1960. The human lung. Newyork: pp.139141, 206-208.

JONES, A. W. AND C. RADNOR. 1972. The development of the chick tertiary bronchus. II. The origin and the mode of production of the osmiophilic inclusion body. Journal of Anatomy. 113: 303-324.

KING A. S. AND J. MCLELLAND. 1984. Birds: Their Structure and Function. London: Ballie're Tindall.

KLAUS, M. H., O. K. REISS, W. H. TOOLEY, C. PIEL, AND J.A. CLEMENTS. 1962. Alveolar epithelial cell mitochondria as source of the surface active lung lining. Science. 137: 750.

MAINA, J. N., A. S. KING, AND G. SETTLE. 1989. An allometric study of the pulmonary morphometric parameters in birds, with mammalian comparison. Philosophical Transactions of the Royal Society of London. Series B. 326: 1-57.

MAINA, J. N. 2003. A systematic study of the development of the airway (bron- chial) system of the avian lung from days 3 to 26 of embryogenesis: a transmission electron microscopic study on the domestic fowl, Gallus gallus variant domesticus. Tissue Cell. 35: 375-391.

MAINA, J. N. 2005. The Lung-Air Sac System of Birds. Berlin: Springer.

MAINA, J. N. 2008. Functional morphology of the avian respiratory system, the lung-air sac system: efficiency built on complexity. Journal of African Ornithology. 79(2): 117-132.

MAINA, J. N. 2010. Implicit mechanistic role of the collagen, smooth muscle, and elastic tissue components in strengthening the air and blood capillaries of the avian lung. Journal of Anatomy, 217(5): 597-608.

MAINA, J.N. AND A. S. KING. 1982. The thickness of avian blood gas barrier: qualitative and quantitative observations. Journal of Anatomy. 134: 553-562.

MIANA, J.N., M.A. ABDALLA, AND A.S. KING. 1982. Light microscopic morphometry of the lungs of 19 avian species. Acta Anatomica. 112: 264-270.

MAKANYA, A.N., Y. El-DARAWISH, B.M. KAVOI, AND V. DJONOV. 2011. Spatial and functional relationships between air conduits and blood capillaries in the pulmonary gas exchange tissue of adult and developing chickens. Microscopy Research and Technique. 74(2): 159-69.

MAYER, G. 2000. Tiny hoopoe-like birds form the middle Eocene of Messel (Germany). Auk, 4: 464-940.

MILLER, D. A. AND S. BONDURANT. 1961. Surface characteristics of vertebrate lung extracts. Journal of Applied Physiology. 16: 1075-1077.

PATTLE, R. E. 1958. Properties, function and origin of the alveolar lining layer. Proceedings the Royal of Society of London. Series B, 148: 217-240.

PATTLE, R.E. 1963. The lining layer of the lung alveoli. Brit. Med. Bull. 79: 41-44.

PATTLE, R.E. 1978. Lung surfactant and lung lining in birds. In: Respiratory Function in Birds, Adult and Embryonic. J. Piiper, ed. Springer-Verlag, Heidelberg, New York, pp. 23-32.

PATTLE, R. E. AND D.A.W. HOPKINSON. 1963. Lung lining in bird, reptile and amphibian. Nature, 200: 894.

RITCHSON, G. 2009. "BIO 554/754 - Ornithology: Avian respiration". Department of Biological Sciences, Eastern Kentucky University.

SCHIED, P. 1979. Mechanisms of gas exchange in bird lungs. Reviews of Physiology, Biochemistry and Pharmacology. 86: 137-186.

THARWAT, M. E. 1997. Birds known to occur in Egypt. Cairo Egypt, pp. 121-122.

TYLER, W. S. AND J. PANGBORN. 1964. Laminated membrane surface and osmiophilic inclusions in avian lung epithelium. Journal of Cell Biology, 20: 157-164.

Received September 12, 2013

Accepted October 26, 2013 